\title{
Analysis of deformation of Cotton in Technological processes
}

\author{
Azim Parpiev ${ }^{1}$, Mamura Sharakhmedova ${ }^{2}$, Anvarjon Parpiev ${ }^{3}$ \\ ${ }^{1,2,3}$ Department of Primary Processing of Natural Fibers, Tashkent Institute of Textile and Light Industry, \\ Tashkent, Uzbekistan, ozod4103@gmail.com
}

\begin{abstract}
Cotton is a material with a specific property as the object of primary processing, consisting of individual fibers of fibrous fibers connected by bonding with each other. As a result of mechanical action in technological processes, the strength of the interconnection of fiber bundles connecting the seeds is reduced, and they undergo deformation. However, it gradually breaks down into individual seeds. The efficiency of the cotton ginning process and the quality of the fiber depends on the structure and size of the cotton, which makes it necessary to prepare the structure for the technological process. In the article is studied the laws of deformation, i.e. elongation or compression, movement of cotton as a result of mechanical action in technological processes, the influence of the direction of mechanical impact on the shape of the deformation point of the cotton piece relative to the location of seeds in it. Considering that the Paxia piece consists of 6 fibrous seeds, the laws of their movement as a result of mechanical action have been developed. In different variants of the cotton-mechanical effect are obtained graphs of the time of movement of fibrous seeds, the relationship of velocities with time. Based on their analysis, it is shown that as a result of the interaction of elementary seeds in a piece of cotton, there is a possibility of the formation of defects that lead to the crushing of defective mixtures, the need for theoretical and practical research in this area.
\end{abstract}

Key words: Cotton, Fibrous Material, Pile and Saw Cylinders, Cleaning Efficiency, Cotton Structure Composition, Cleaning Frequency, Fibrous Single Seed.

\section{INTRODUCTION}

It is known that a piece of cotton picked from a cotton ball consists of 6-9 fibrous seeds, the longitudinal section of which is ellipsoidal in length. Cotton is deformed by stretching along its length during harvesting [1]. The cotton is then deformed during cart loading, unloading, transfer and bagging, production transfer, pneumatic transport, separator, drying cylinder and cleaning equipment [2].

Due to the fact that the deformation of cotton and the structure of the structure are important for cleaning and ginning, the definition of the laws of its deformation under mechanical influences is an urgent task for the effective organization of technological processes [3]. Cotton deformation is manifested in the forms of elongation, compression, bending and twisting. Therefore, the impact of each technological process on the structure of cotton should be considered separately [4]. The effect of a piece of cotton on the composition of the structure by technological processes, including cleaning, has been studied by a number of researchers $[5,6,7]$. The effect on cleaning efficiency was determined.

The object of drying of cotton was studied by researchers $[8,9]$, the coefficient of the degree of shredding of cotton was developed and it was possible to determine the specific surface area in the process of cotton construction $[10,11]$.

One of the peculiarities of cotton as an object of cleaning is its degree of deformation, i.e. the elongation of cotton pieces into separate fibrous lines. The reason is that the more deformed the piece of cotton, the greater the specific surface area of its porosity. As a result, conditions are created for the separation of impurities between the fibers $[12,13]$.

Defective compounds in the produced fiber content, such as curls, tow and combined tow, are based on a number of researchers $[14,15]$ who believe that the formation of fiber occurs as a result of the interaction of detergents with the composition of the structure in the cotton cleaning process.

Therefore, in the production of quality fiber, the optimal preparation of cotton for the cleaning process of the structural composition is important.

The purpose of the article is to determine the laws of deformation of cotton under mechanical influences, which we will consider in general $[16,17]$.

\section{MATERIALS AND METHODS}

\subsection{The theory of cotton deformation}

Suppose a piece of cotton contains $n$ seeds of the same mass $\mathrm{m}$, which are interconnected by elastic fibers. (Figure 1)

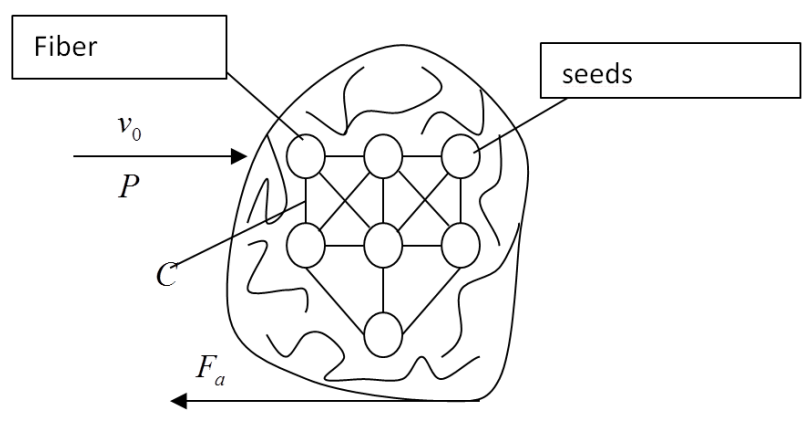

Figure 1: Scheme of seed placement on a piece of cotton 
Azim Parpiev et al., International Journal of Emerging Trends in Engineering Research, 8(9), September 2020, 6618 - 6622

For clarity, we assume that $\mathrm{n}=6$.

Let the mechanical impact be given in the direction in which the masses 1 and 2 are located. (Figure 2, scheme 1) The equation of motion of seeds:

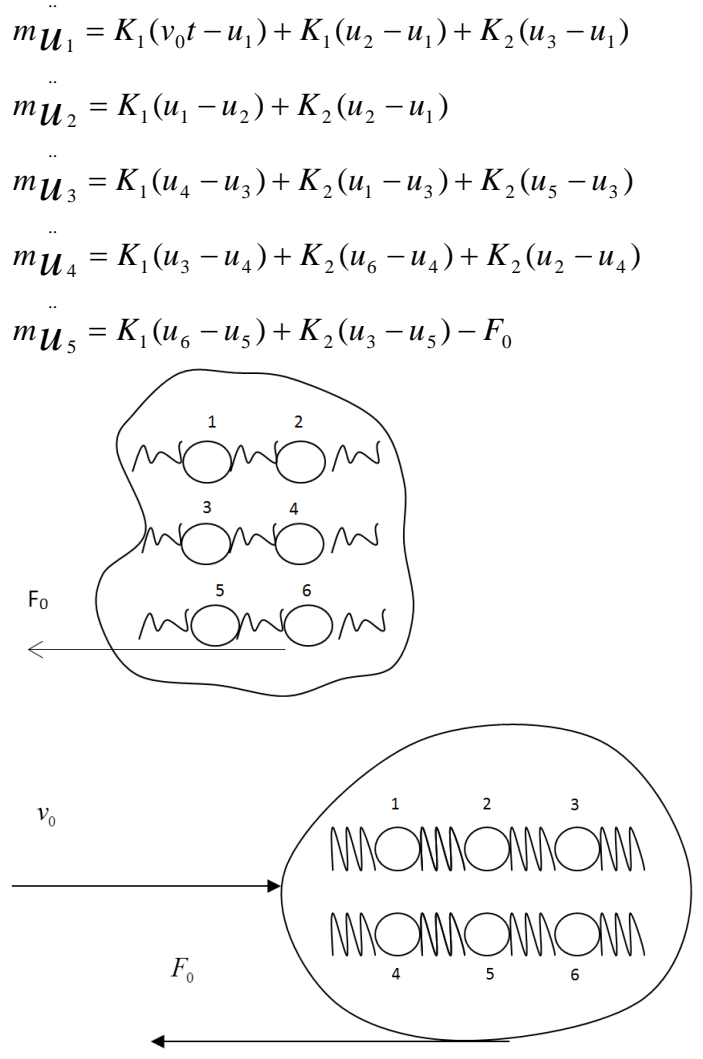

Figure 2: Seed cotton mechanical impact factors

${ }^{m} \boldsymbol{u}_{5}$ - Seed mass and velocities, $\mathrm{t}$ - time, $v_{0}$ - the initial velocity of the cotton piece, $K_{1}$ and $K_{2}$-the coefficients of elasticity of the elastic elements placed in the horizontal and vertical directions in compression $\left(K_{1}\right)$ and displacement $\left(K_{2}\right), F_{0}$-friction force with the mesh surface.

$u_{1}(0)=u_{2}(0)=u_{3}(0)=u_{4}(0)=u_{5}(0)=u_{6}(0)=0$

$\boldsymbol{u}_{1}(0)=\boldsymbol{u}_{2}(0)=\dot{u}_{3}(0)=\dot{u}_{4}(0)=\dot{u}_{5}(0)=\dot{u}_{6}(0)=0$

The system of equations is solved using a computer. If the shock is applied to masses 1 and 2 , then the third equation of the system is as follows.

$m \ddot{\boldsymbol{u}}_{5}=K_{1}\left(v_{0} t-u_{5}\right)+K_{1}\left(u_{6}-u_{5}\right)+K_{2}\left(u_{3}-u_{5}\right)-F_{0}$

$v_{0}$ - Speed transmitted to the particle by impact.

If the seeds are arranged in two rows in the plot (Figure 2, scheme 2).

In this case, the equations can be written as follows.

$$
\begin{aligned}
& m \ddot{\boldsymbol{U}_{1}}=K_{1}\left(v_{0} t-u_{1}\right)+K_{1}\left(u_{2}-u_{1}\right)+K_{2}\left(u_{3}-u_{2}\right)+K_{2}\left(u_{4}-u_{1}\right) \\
& \ddot{\boldsymbol{U}_{2}}=K_{1}\left(u_{1}-u_{2}\right)+K_{1}\left(u_{3}-u_{2}\right)+K_{2}\left(u_{5}-u_{2}\right) \\
& \ddot{\boldsymbol{U}_{3}}=K_{1}\left(u_{2}-u_{3}\right)+K_{2}\left(u_{6}-u_{3}\right) \\
& \ddot{\boldsymbol{U}_{4}}=K_{1}\left(u_{5}-u_{4}\right)+K_{2}\left(u_{1}-u_{4}\right)-F_{0} \\
& { }^{m} \ddot{\boldsymbol{U}}_{5}=K_{1}\left(u_{4}-u_{5}\right)+K_{1}\left(u_{6}-u_{5}\right)+K_{2}\left(u_{2}-u_{5}\right)-F_{0} \\
& \ddot{\boldsymbol{U}_{6}}=K_{1}\left(u_{5}-u_{6}\right)+K_{2}\left(u_{6}-u_{3}\right)-F_{0}
\end{aligned}
$$

If the stroke is doubled, it changes the fourth equation.

$$
m \ddot{\boldsymbol{u}_{4}}=K_{1}\left(v_{0} t-u_{4}\right)+K_{1}\left(u_{5}-u_{4}\right)+K_{2}\left(u_{1}-u_{4}\right)-F_{0}
$$

\section{RESULTS AND DISCUSSION}

\subsection{Experimental results and their analysis}

$$
\omega_{1}=\sqrt{k_{1} / m}, \omega_{2}=\sqrt{k_{2} / m} \text { Two values of velocity }
$$
using parameters (parameters) $v_{0}=1 \mathrm{~m} / \mathrm{s}$ and $0.3 \mathrm{~m} / \mathrm{s}$ the accounting work was performed on the computer, it was accepted as the Account $\omega_{1}=60, \omega_{2}=40$

The calculation results are shown in figures 3 and 4 .
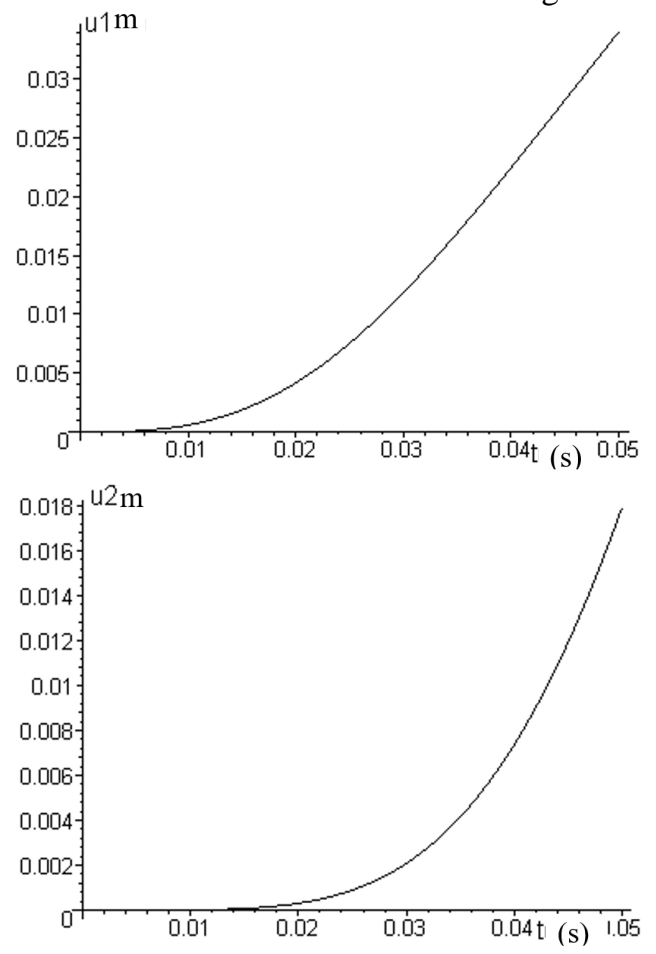
Azim Parpiev et al., International Journal of Emerging Trends in Engineering Research, 8(9), September 2020, 6618 - 6622
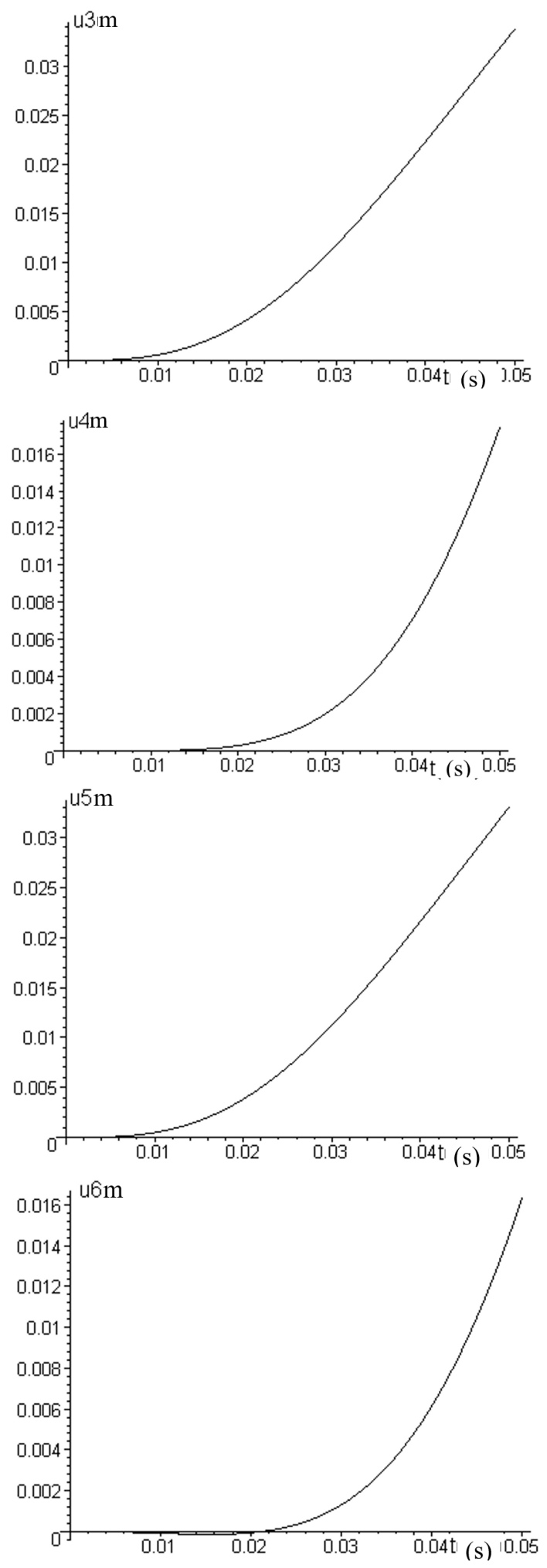

Figure 3: The laws of motion according to the first calculation scheme in the presence of seeds $v_{0}=1 \mathrm{~m} / \mathrm{s}$ in the composition of the fraction
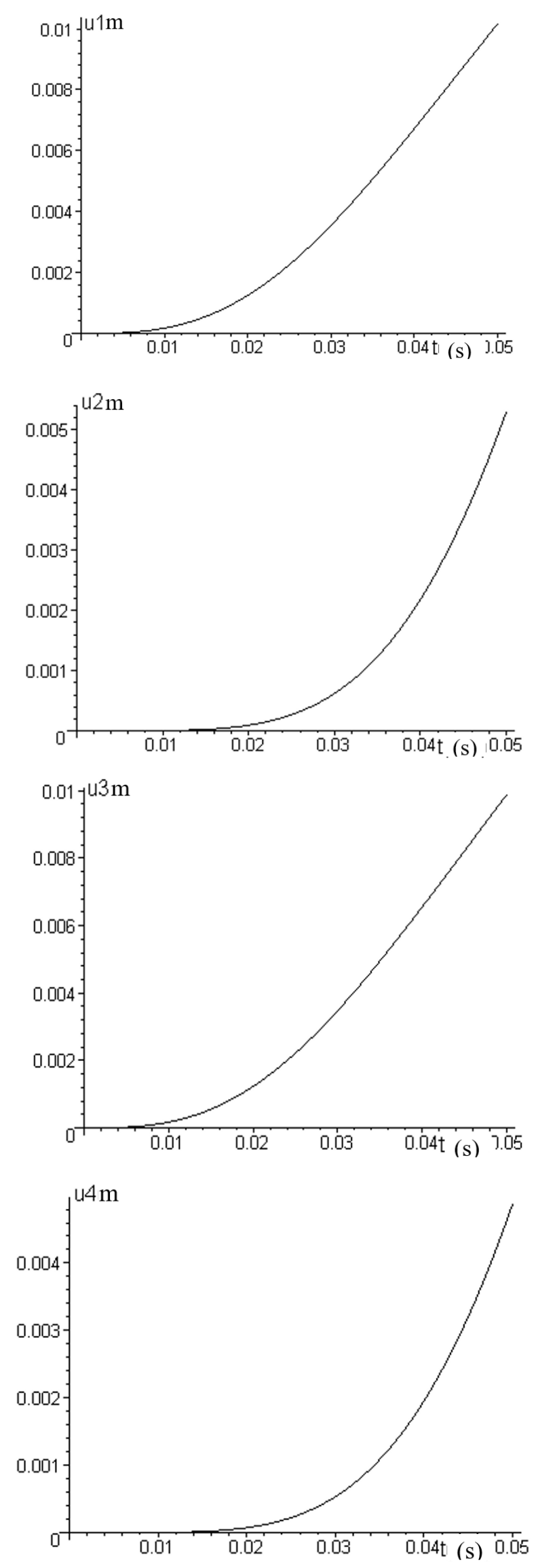

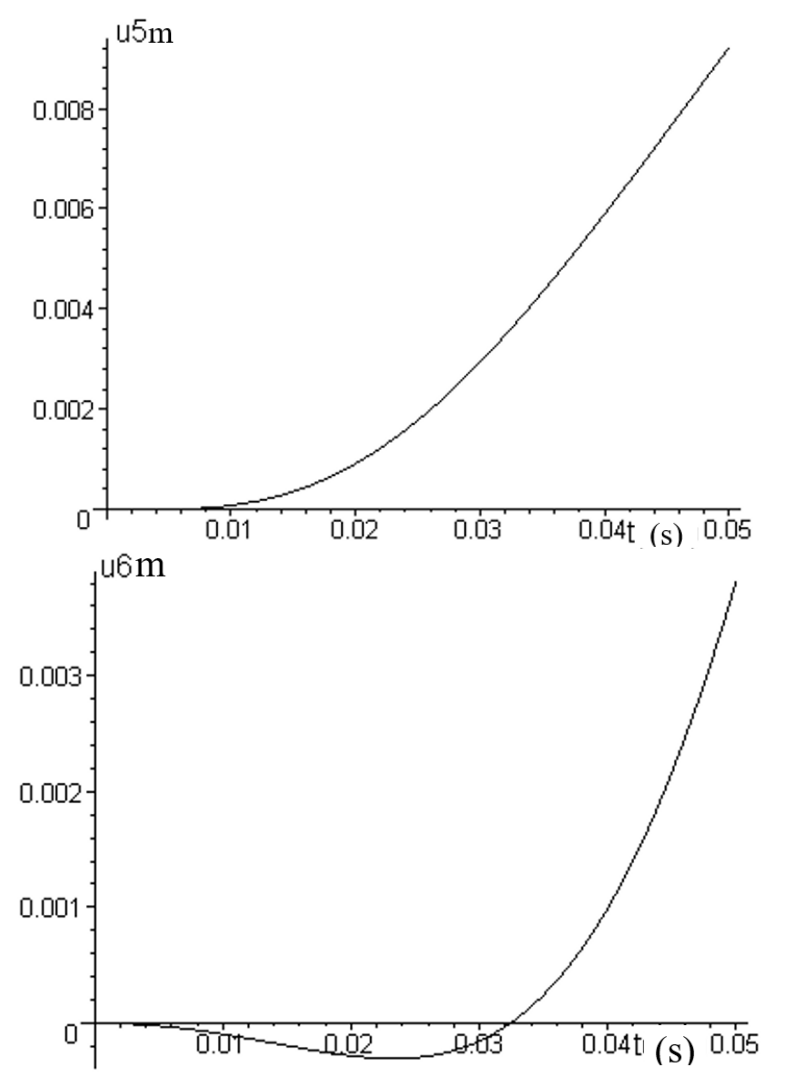

Figure 4: The laws of motion over time in the first calculation scheme $v_{0}=0.3 \mathrm{~m} / \mathrm{s}$ in the presence of seeds in the fraction

If the mechanical impact of cotton is given in the direction of the impact masses 1 and 2, i.e. according to Scheme 1: the time of movement varies depending on the location of the mechanical force acting on the seeds, faster in seeds 1,3 and 5 , and relatively later in seeds 2,4 and 6 begins. That is, the state $t_{1} \prec t_{3} \prec t_{5} \prec t_{2} \prec t_{4} \prec t_{6}$ occurs at the time of movement. In this case, if the spacing of seeds $1-2$ and 2-3 is subjected to elongation deformation, then in the range of +-2 , 2-4, 4-6 seeds compression deformation occurs and leads to an increase in density [17]. As a result, contaminants in these intervals can be crushed and the force of bonding with the fiber can be activated. The recorded deformation times depend on the values of $t_{1}-t_{3}=\Delta t_{1,3}, t_{3}-t_{5}=\Delta t_{3,5}$, $t_{2}-t_{4}=\Delta t_{2,4}$ and $t_{4}-t_{6}=\Delta t_{4,6}$.

In seeds 1,3 and 5, which are subject to elongation deformation, the change in velocities with the onset of motion, i.e., the growth is relatively high in the axis and is also greater than in the velocities 2, 4 and 6. Due to the time of movement and the difference in speed during elongation, the distance between the seeds increases and the separation process begins in the fiber sections. Due to repeated, mechanical shocks, the seeds that are in contact can separate and turn into separate fibrous individual seeds [18]. If the mechanical effect on the cotton is given in scheme 2 , the time of movement of seeds 2 and $5 t_{2}$ and $t_{3}$ increases significantly, in the first minutes of mechanical action there is a movement in the opposite direction to the direction of impact, i.e. compression occurs and after a short time the direction of movement changes begins.

In seeds 2,4 and 6, the onset of motion occurs at $t_{2} \succ t_{4} \succ t_{6}$. The 6th seed moves in the direction of compression for some time.

\subsection{The speed of movement of seeds varies sharply}

At other values of the mechanical impact pulse rate, $v_{0}=0.3 \mathrm{~m} / \mathrm{s}$ and $v_{2}=2 \mathrm{~m} / \mathrm{s}$, in the reports obtained in

Fig. 1 the fact that the laws of change of time of onset of movement and speed of seeds under the influence are preserved only showed that as the speed decreases, the times and speeds of movement of seeds also decrease $[19,20]$.

It was found that when the pulse is given according to scheme 2 , its velocity decreases, drastically changing the time of movement of the seeds and affecting the nature of the law of change of velocities. It was found that seeds 3 and 6 work in the opposite direction of compression rather than elongation $[21,22,23]$.

\section{CONCLUSION}

The analysis of the obtained results leads to the following conclusions: mechanical impact on a multi-seeded cotton piece, i.e. the law and direction of movement of fibrous individual seeds, which are an elementary piece of cotton, are different depending on the speed and direction of impact point, it can be compressed or elongated.

Considering that the degree of elongation and friction in the ginning process has a positive effect on the ginning efficiency, there is a need to determine the structure of the cotton and the rational speed and direction of the influencing forces in order for the individual grains to work in the gin. Theoretical and practical research in this area is ongoing.

\section{REFERENCES}

1. Tuychiev T.O. Preparation for the technological process of ginning cotton and increasing the efficiency of the ginning machine by improving the supplier, Doctor of Philosophy in Technical Sciences (PhD). Tashkent, 2018. $120 \mathrm{p}$.

2. Wa Z., Vang Y., Huang G., Cotton functional genomics reveals global insight into gehome evolation and fiber development, foutnol of Geneties and Genomics 44, 2017, pp. 511-518

3. Tuychiyev T.O., Madumarov I.D., Mardonov B.M., Investigation of the process of releast of dirt impurities in the zone of interaction of it with a netlike surface, 
Azim Parpiev et al., International Journal of Emerging Trends in Engineering Research, 8(9), September 2020, 6618 - 6622

European Science Review. 2017, 9-10, pp.130-133.

4. Muradov R.M. Fundamentals of increasing the efficiency of the transport process in the technology of primary processing of cotton, Doctor of technical sciences. diss. Tashkent, 2004, 205 p.

5. Parpiev A.P., Mardonov B, Madumarov I.D., Tuychiev T.O. Modeling the movement of the mass of raw cotton in the zone of feeders, Problems of textiles, 2013 No. 1 pp. 80-86.

6. Tuychiev T. O., Madumarov I. D., Parpiev A. P. The effect of geometric dimensions of the mine collector on the efficiency of equipment cleaning. Problems of textiles, 2010, pp. 12-16.

7. Madumarov I.D. Improving the efficiency of the cleaning process on the basis of alternating heat and humidity conditions and ensuring a uniform supply of cotton. Ph.D. diss. Tashkent, 2019, $210 \mathrm{p}$.

8. Juraev Anvar and Rajabov Ozod. Analysis of the interaction of Fibrous Material with a Multifaceted Grid of the cleaner, International Journal of Recent Technology and Engineering, vol. 8, 1, 2019, pp. 2661-2666.

9. Juraev and O. Rajabov. Experimental study of the interaction of multifaceted and cylindrical spiky cylinder in cotton cleaner from small waste, International Journal of Advanced Research Science. Engineering and Technology, vol. 6, 3, 2019, pp. 8382-8387.

10. O. Rajabov, K. Fazliddin, and Sh. Salimov. Substantiation of Parameters of the Fibrous Material Cleaning Zone, International Journal of Engineering and Advanced Technology, vol. 9, 3, 2020, pp. 1052-1057.

11. O. I. Rajabov, A. S. Abrorov, N. I. Mirzaqulova, G. B. Zaripov and $\mathrm{Kh}$. S. Ziyodullaev. An experimental study of the location of the grid bars cells installed under spiked cylinders in a cotton cleaner from small waste, IOP Conference Series: Materials Science and Engineering, 2020, 862032049.

12. Ozod Rajabov, Fazliddin Kurbonov, Mastura Gapparova and Shakhrillo Jumaev. The influence of the location of the cells on the allocation of weed impurities for cleaning raw cotton from fine waste, IOP Conference Series: Materials Science and Engineering, 2020, 862032027.

13. Akbar Abrorov, Matluba Kuvoncheva, Ozod Rajabov, Mukhsin Mukhammadov and Shakhrillo Jumaev. Method of thermal treatment of saw disk teeth of fiber- processing machines by laser quenching, IOP Conference Series: Materials Science and Engineering, 2020, 862032034.

14. Z. Shodiyev, A. Shomurodov and O. Rajabov. The results of the experimental nature of the vibrations of the grid cotton cleaner, IOP Conference Series: Materials Science and Engineering, 2020, 883 012169 https://doi.org/10.1088/1757-899X/883/1/012169

15. Deshmukh D. T. and Lunge H. S. Impact of Global Warming on Rainfall, And Cotton Lint With
Vulnerability Profiles of Five Districts In Vidarbha, International Journal of Scientific \& Technology Research, vol. 1, is. 11, 2012. pp. 77-85.

16. Rajabov Ozod Isroilovich, The influence of the mode of movement of the pieces cotton when interacting with a cotton grid, International Journal of Advanced Research in Science, Engineering and Technology. Vol. 6, Issue 3, (2019). pp. 8455-8381.

17. Ozod Rajabov and Ziyodullo Shodiyev, Analysis of Small Fluctuations of a Multifaceted Mesh under the Influence of Technological Load from the Cleaned Cotton - Raw, International Journal of Advanced Research in Science, Engineering and Technology, Vol. 6, Issue 10, (2019), pp. 11396-11399.

18. Bekhruz Gaybulloev, Nigina Ergasheva, Ozod Rajabov, The Structure of the Embroidery Machine and Dynamic Analysis of the Needle Mechanism, International Journal of Advanced Research in Science, Engineering and Technology, Vol. 7, Issue 1, (2020). pp. 8376-8381.

19. Anvar Djuraev and Ozod Isroilovich Rajabov, Substantiation of the main parameters of the cylinder with multifaceted spiked of the cotton cleaner from small waste, International scientific and practical conference Innovative ideas of modern youth in science, (2019), USA. pp. 149-151.

20. Mavlyanov Aybek Palvanbaevich, Rajabov Ozod Isroilovich and Yakubova Aziza Vakil qizi, Study of the influence of the parameters of the plastic grate on elastic supports with nonlinear stiffness on the oscillation frequency, International scientific and practical conference "Innovative ideas of modern youth in science", 2019, pp. 152-154.

21. Smirnova Zhanna.V, Vaganova O.I., Chaykina Zh. V., Golubeva O.V. Calculation of metallurgical processes during welding, International Journal of Emerging Trends in Engineering Research, Volume 8. No. 5, May 2020, pp. 1529-1534.

22. A.M.Mahaboob Basha, M.Rajaiah, P.Penchalaiah, CH.Raja Kamal, B.Niranjana Rao. Machine Learning-Structural Equation Modeling Algorithm: The Moderating role of Loyalty on Customer Retention towards Online Shopping, International Journal of Emerging Trends in Engineering Research, Volume 8. No. 5, May 2020, pp. 1578-1585.

23. Ozod Rajabov, Ziyodullo Shodiyev, Ikrom Inoyatov, Mastura Gapparova. Analysis of the Technological Process of Cleaning Raw Cotton from Small Trash, International Journal of Emerging Trends in Engineering Research, Volume 8. No. 9, September 2020, pp. 6022-6029. 